\title{
The diagnostic accuracy of ultrasound in the detection of foot and ankle fractures: a systematic review and meta-analysis
}

\author{
Jiangfeng Wu*, Yunlai Wang*, Zhengping Wang \\ * the authors shared the first authorship
}

Department of Ultrasound, Affiliated Dongyang Hospital of Wenzhou Medical University, Dongyang, Zhejiang, China

\begin{abstract}
Aims: Foot and ankle injuries are a common presenting complaint in the emergency department. The diagnosis of foot and ankle fractures is conventionally accomplished through X-rays. Whether ultrasound (US) can be considered as a primary scanning modality is still a controversial issue; therefore, we did a meta-analysis to synthesize the diagnostic performance of ultrasound for foot and ankle fractures. Material and methods: A comprehensive search was carried out to identify studies in which patients with clinically suspected foot and ankle fractures were assessed by US. Two investigators independently screened the literature and extracted the data. Any discrepancies were resolved via discussion. Study quality was assessed by the Quality Assessment of Diagnostic Accuracy Studies 2 tool, and pooled sensitivity and specificity of various US findings were determined. Results: Ten studies with a total of 1065 patients were included. There was significant heterogeneity across the included studies. The pooled sensitivity, specificity, positive likelihood ratio, negative likelihood ratio, and diagnostic odds ratio for the diagnosis of foot and ankle fractures by US were 0.96 (95\% confidence interval [CI], 0.90-0.99), 0.94 (95\% CI, 0.88-0.97), 15.0 (95\% CI, 7.9-28.6), 0.04 (95\% CI, 0.02-0.11), and 367 (95\% CI, 101-1338), respectively. Furthermore, the summary receiver operating characteristic area under the curve was calculated to be 0.99 . Conclusions: Ultrasound has an excellent diagnostic performance for foot and ankle fractures and should be considered as a primary and radiation-free scanning modality in the diagnosis of foot and ankle fractures.
\end{abstract}

Keywords: ultrasound; foot and ankle fractures; meta-analysis; systematic review; diagnostic accuracy

\section{Introduction}

Foot and ankle injuries are a common presenting complaint to the emergency department (ED), which occur as buckling or blunt trauma and generally lead to a strain, sprain, or, more rarely, fracture [1,2]. Although such injuries are not usually fatal, the functions of the affected limb can be imperilled, and therefore, early diagnosis and treatment are exceedingly significant for pa-

Received 06.06.2020 Accepted 25.09.2020

Med Ultrason

2020:0 Online first, 1-10

Corresponding author: Jiangfeng $\mathrm{Wu}$

Department of Ultrasound, Affiliated Dongyang

Hospital of Wenzhou Medical University

60 Wuning West Road, Dongyang (322100),

Zhejiang, China

E-mail:wjfhospital@163.com

Phone: 18257937213 tients with foot and ankle fractures to prevent long-term complications [3].

The diagnosis of foot and ankle fractures is conventionally accomplished through X-ray, which is usually considered as the standard reference [4]. Whereas, the $\mathrm{X}$-ray entails exposure to ionizing radiation with its attendant possible carcinogenic and teratogenic effects $[5,6]$. Alternative imaging modalities, such as computed tomography $(\mathrm{CT})$, magnetic resonance imaging (MRI) and ultrasound (US), have been considered to improve the diagnostic accuracy of foot and ankle fractures $[7,8]$. However, selection of CT examination as the standard reference will bring overmuch and sometimes unnecessary ionizing radiation to patients and MRI is related to increased and unnecessary time and expense [5,7].

In the recent years, ultrasound has emerged as a possible alternative for the diagnosis of bone fractures in the $\mathrm{ED}$, which has been reported to have a high accuracy in 
pediatric elbow, distal radius, metacarpal, phalanx, ankle and metatarsal fractures [9-12]. One of the main advantages of ultrasound is the lack of ionizing radiation. Furthermore, ultrasound can be immediately performed and is easily accessible in the ED, reducing diagnostic delays and the time to the initiation of management. Additional advantages of ultrasound include the relative easiness to teach [13], reduced pain experience [14], repeatability, portability, and the provision of additional information regarding the musculoskeletal system [15-17].

Whether ultrasound can be considered as a primary scanning modality is still a controversial issue, as the diagnostic accuracy of ultrasound for detecting foot and ankle fractures is variable across different studies. Prior studies assessing the accuracy of US in the diagnosis of foot and ankle fractures have been published, with the sensitivity ranging from $83 \%$ to $100 \%$ and the specificity ranging from $76 \%$ to $100 \%$ [18-20]. To our knowledge, no studies have comprehensively evaluated the literature on foot and ankle fractures diagnosis using ultrasound. Hence, we did a meta-analysis to synthesize the diagnostic performance of ultrasound for foot and ankle fractures.

\section{Material and methods}

\section{Meta-analysis principles}

This meta-analysis was conducted according to the Preferred Reporting Items for Systematic Reviews and Meta-Analyses (PRISMA) guidelines, which include 27 items and provide specific guidance for the reporting of systematic reviews [21].

\section{Search strategy}

Pubmed, EMBASE and Cochrane Library were systematically searched to identify potentially eligible studies from inception to March 2020. Computer searches were carried out using the Medical Subject Heading and keywords. Detailed search terms are provided in supplementary file 1 . The bibliographies of identified studies and review articles were manually screened to expand the number of eligible studies. Only studies in English, which satisfied the inclusion criteria, were included.

\section{Inclusion and exclusion criteria}

Two researchers (JW and YW) independently screened the titles and the abstracts of the potentially eligible studies. Before identifying the literature, inclusion and exclusion criteria were defined to increase validity and reproducibility. Any disagreements between the two researchers were resolved via discussion with the senior author (ZW).

The inclusion criteria were as follows: (1) randomised control trials and prospective studies were included; (2) studies involving patients with clinically suspected foot and ankle fractures; (3) the accuracy of ultrasonography in the diagnosis of foot and ankle fractures was evaluated and (4) a reference standard was adopted to confirm foot and ankle fractures, including X-ray, computed tomography, and/or magnetic resonance imaging.

The exclusion criteria were as follows: (1) case reports, letters, guidelines, consensus statements, and unpublished articles; (2) studies that contained an overlapped population and (3) studies without sufficient data to construct diagnostic $2 \times 2$ tables.

\section{Data extraction}

Two researchers (JW and YW) independently extracted the relevant data from the included studies using a pre-designed data collection form. Any discrepancies were resolved via discussion with the senior author (ZW). For eligible studies, the following items were extracted: last name of the first author, year of publication, country, study type, study setting, blinding method, US equipment, probe frequency, sample size, number with fractures, fracture prevalence, fracture site, mean age, gender, US operator specialty, examiner training, US diagnostic criteria, standard reference, time between ultrasonography and the standard reference, true positives, true negatives, as well as false positives and false negatives of US in the diagnosis of foot and ankle fractures.

\section{Study quality assessment}

The Quality Assessment of Diagnostic Accuracy Studies-2 (QUADAS-2) tool [22] was utilized to evaluate the risk of bias and methodological quality. The quality of each included study was evaluated by an appraisal of the risk of bias of four domains and clinical applicability of three domains of the study characteristics. Four domains consisted of patient selection, index test, reference standard and flow and timing. Each domain was evaluated for risk of bias, and the first three domains were evaluated for applicability. The processing of the quality assessment was performed utilizing RevMan 5.3 software (Nordic Cochrane Centre, Copenhagen, Denmark).

\section{Statistical analysis}

The present meta-analysis was conducted by Stata 12.0 (Stata Corporation, College Station, Texas). All statistical analyses were performed by one investigator, who has experience in performing meta-analysis. The summary estimates of sensitivity, specificity, positive likelihood ratio (PLR), negative likelihood ratio (NLR) and diagnostic odds ratio (DOR) with corresponding 95\% confidence intervals (CIs) were calculated using a bivariate random effect model in the present analysis, which indicated the accuracy of US in the diagnosis of foot and ankle fractures. Meanwhile, the summary receiver operator curve (SROC) was constructed and the area under the curve (AUC) was calculated. An AUC close to 0.5 
shows a poor test, while an AUC of 1.0 demonstrates an excellent diagnostic test [23]. We applied the spearman correlation analysis to determine whether a threshold effect is present, with $p<0.05$ representing a threshold effect. The Cochrane Q test and the inconsistency index $\left(\mathrm{I}^{2}\right)$ were used to assess the heterogeneity among different studies with a p-value $<0.1$ or $\mathrm{I}^{2}>50 \%$ considered significant for heterogeneity [24].

Meta-regression analyses utilizing several covariates were carried out to investigate the potential causes of heterogeneity: country (Turkey versus countries other than Turkey), sample size ( $>100$ versus $\leq 100)$, fracture prevalence ( $>30 \%$ versus $\leq 30 \%$ ), year published (20092013 versus 2014-2019), reference standard (only X-ray versus including $\mathrm{CT}$ or MRI), ultrasonographic operator (emergency physician versus others), ultrasonographic training (yes versus others), blinding method (double blinding versus others), and bedside ultrasound (yes versus others). The Deeks' funnel plot asymmetry test was applied to assess publication bias [25], through a $\mathrm{p}$ value $>0.05$ denoting no significant publication bias.

\section{Results}

\section{Study selection}

The initial search for studies which assessed the diagnostic performance of US for foot and ankle fractures provided 1818 studies, of which 1217 relevant studies remained after removing 601 duplicate studies. We re-

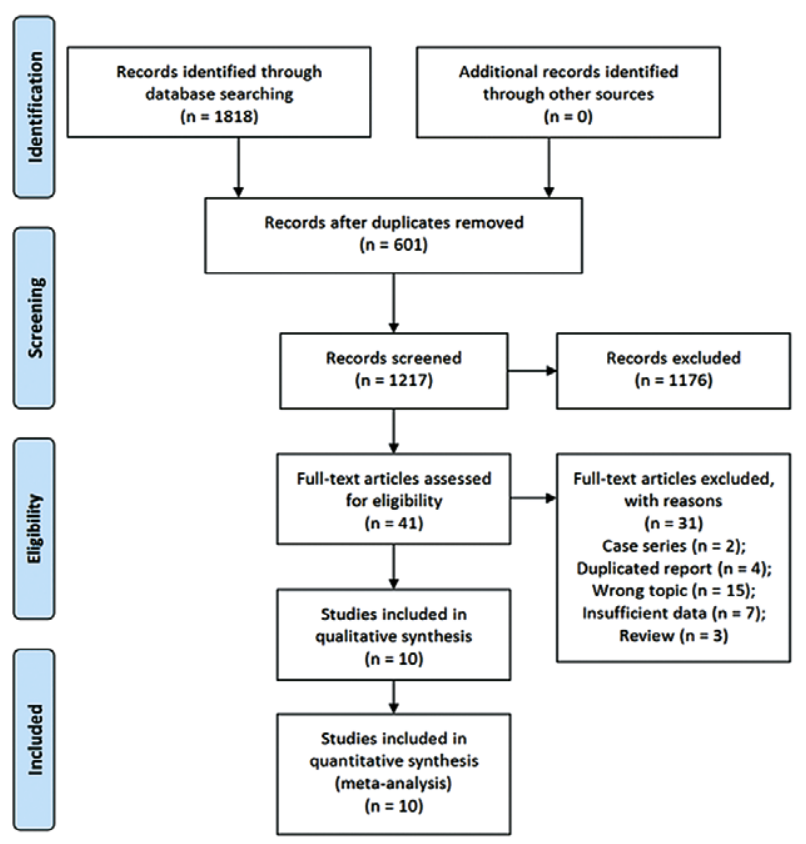

Fig 1. Preferred Reporting Items for Systematic Reviews and Meta-Analyses (PRISMA) flowchart of the search process viewed 1217 titles and abstracts and then excluded 1176 studies because it was obvious from the title or abstract that they were not relevant to this meta-analysis. Full text of the remaining studies was reviewed, and another 41 studies were excluded. Finally, 10 original research studies were included in the present meta-analysis [18-20,2632]. Manual searching of the reference cited in these 10 studies did not yield any additional relevant studies. Figure 1 shows a flow diagram summarizing the literature.

\section{Characteristics of the included studies}

The 10 included studies with a total of 1065 patients were published between 2009 and 2019 and written in English. Five studies were conducted in Turkey [20,2831], 1 was performed in France [18], 1 in Israel [19], 1 in England [26], 1 in Sweden [27], and 1 in Iran [32]. All were prospective observational studies. The number of patients in the study ranged from 37 to $246 ; 48.2 \%$ of patients were male and the mean age ranged from 8.1 to 52.7 years. The prevalence of foot and ankle fractures ranged from $10 \%-40.4 \%$. Nine studies [19,20,26-32] were conducted in ED and 1 was performed in the rheumatology department [18]. Emergency physicians performed the US examination in 5 studies [20,28,30-32], an experienced rheumatologist in 1 study [18], a pediatric radiologist in one study [19], an orthopedic surgeon in one study [27], an ED member in 1 study [26] and a sonographer in 1 study [29]. Double blinding between the standard reference and index tests was found in 7 studies [18,20,26,27,29,31,32], single blinding of the standard reference to US results in 2 studies [19,28] and 1 study [30] did not report a blinding method. In all studies the time interval between US and the standard reference was not given except for the study by Banal et al who declared US and the standard reference were performed on the same day [18]. Three studies included ankle fractures [19,27,31], 3 included foot or ankle fractures $[26,28,29]$ and 4 only included metatarsal fractures $[18,20,30,32]$. Seven studies used the X-ray as the reference standard [19,20,26-28,30,32], 1 used MRI [18] and 2 used X-ray or CT [29,31]. The probe frequency ranged from 5 to $15 \mathrm{MHz}$. Table I and II epitomizes the data extracted from the included studies. More details are showed in supplementary file 2 .

\section{Quality assessment}

The quality assessment results of the risk of bias and applicability concerns of the selected studies were presented graphically in figure 2 .

With respect to the patient selection domain, 1 study was considered as having high bias because the sample was selected by the nonrandom purposive sampling method [32]. 
Table I. Primary data extracted from included studies for meta-analysis

\begin{tabular}{llllllllll}
\hline Author & Year & $\begin{array}{l}\text { Study } \\
\text { type }\end{array}$ & Country & $\begin{array}{l}\text { Sample } \\
\text { size (n) }\end{array}$ & $\begin{array}{l}\text { Number with } \\
\text { fractures (n) }\end{array}$ & $\begin{array}{l}\text { Fracture } \\
\text { (\%) }\end{array}$ & $\begin{array}{l}\text { Male/ } \\
\text { female }\end{array}$ & $\begin{array}{l}\text { Age } \\
\text { (mean } \pm \text { SD) }\end{array}$ & Training \\
\hline Banal [18] & 2009 & Pro & France & 37 & 12 & 32.4 & $9 / 28$ & $52.7 \pm 14.1$ & No \\
Simanovsky [19] & 2009 & Pro & Israel & 41 & 11 & 26.8 & $14 / 27$ & 8.1 & No \\
Canagasabey [26] & 2011 & Pro & England & 110 & 11 & 10.0 & $65 / 45$ & $31.8 \pm 12.7$ & Yes \\
Hedelin [27] & 2013 & Pro & Sweden & 122 & 23 & 18.8 & $58 / 64$ & $42(18-92)$ & Yes \\
Ekinci [28] & 2013 & Pro & Turkey & 131 & 20 & 15.2 & $64 / 67$ & $37.2 \pm 15.44$ & Yes \\
Atilla [29] & 2014 & Pro & Turkey & 246 & 76 & 30.9 & $105 / 141$ & 37 (median age) & Yes \\
Yesilaras [20] & 2014 & Pro & Turkey & 84 & 34 & 40.4 & $36 / 48$ & $36 \pm 15$ & No \\
Kozaci [30] & 2017 & Pro & Turkey & 72 & 28 & 38.8 & $48 / 24$ & $33 \pm 18$ & Yes \\
Ozturk [31] & 2018 & Pro & Turkey & 120 & 42 & 35.0 & $57 / 63$ & $40.8 \pm 19.3$ & Yes \\
Ebrahimi [32] & 2019 & Pro & Iran & 102 & 31 & 30.3 & $58 / 44$ & $35.14 \pm 14.32$ & NR \\
\hline
\end{tabular}

Pro, prospective; NR, not reported; SD, standard deviation

Concerning the index test domain, 1 study [30] was considered as "unknown" because the blinded status was not explicitly reported; 2 other studies [27,28] were also labelled as "unknown" because they did not explicitly report the diagnostic threshold. Regarding the reference standard domain, 3 studies $[19,28,30]$ were considered as "unknown" because the blinded status was not explicitly reported. With regard to the flow and timing domain, 9 studies were considered as "unknown" because they did not definitely report the time interval between US and the reference standard [19,20,26-32].

Regarding applicability, for patient selection, index test, and reference standard domains, all studies were considered to have low concerns.

\section{Data synthesis}

Overall, ultrasound had a 0.96 (95\% CI, 0.90-0.99) sensitivity and 0.94 (95\% CI, 0.88-0.97) specificity for the diagnosis of foot and ankle fractures (fig 3). The pooled PLR, NLR, and DOR of US were 15.0 (95\% CI, 7.9-28.6), 0.04 (95\% CI, 0.02-0.11), and 367 (95\% CI, 101-1338), respectively and the post-test probability was $79 \%$ and $1 \%$, respectively (fig 4 ). Significant heterogeneity was found for the sensitivity $\left(\mathrm{I}^{2}=51.43 \%, \mathrm{p}=0.03\right)$ and specificity $\left(\mathrm{I}^{2}=81.45 \%, \mathrm{p}=0.00\right)$. The AUC under the SROC curve for the value of US in the diagnosis of foot and ankle fractures was 0.99 (fig 5). The Spearman correlation coefficient was determined to be $-0.127(p=0.726)$, which indicated no significant threshold effect among the individual studies.

The Deeks' funnel plot asymmetry test demonstrated that the studies were distributed symmetrically with a $p$ value of 0.8 (fig 6), which indicated that there was no significant publication bias in the present meta-analysis.

\section{Meta regression and subgroup analyses}

Due to the significant heterogeneity among studies, meta-regression analysis was then conducted to explore

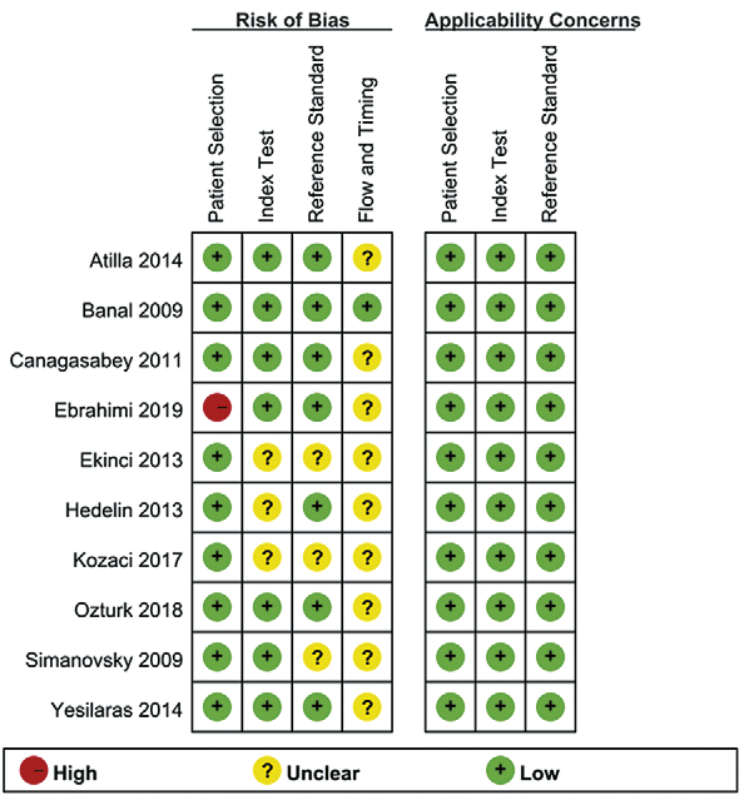

Fig 2. Quality assessment of the included studies using QUADAS-2 tool

other potential sources of heterogeneity. The covariables included the locale (Turkey versus countries other than Turkey), number of patients ( $>100$ versus $\leq 100)$, fracture prevalence ( $>30 \%$ versus $\leq 30 \%$ ), year published (20092013 versus 2014-2019), reference standard (only radiograph versus including CT or MRI), ultrasonographic operator (emergency physician versus others), ultrasonographic training (yes versus others), blinding method (double blinding versus others), and bedside ultrasound (yes versus others).

Among the various potential covariates, the blinding method (double blinding versus others) was associated with the heterogeneity of the sensitivity. With respect to the covariate of the country, studies in Turkey had a 
Table II. Characteristics of the included studies

\begin{tabular}{|c|c|c|c|c|c|c|c|c|c|}
\hline Author & $\begin{array}{l}\text { Fre- } \\
\text { quency } \\
\text { (MHz) }\end{array}$ & $\begin{array}{l}\text { Fracture } \\
\text { site }\end{array}$ & $\begin{array}{l}\text { Blind- } \\
\text { ing }\end{array}$ & $\begin{array}{l}\text { Refer- } \\
\text { ence } \\
\text { standard }\end{array}$ & $\begin{array}{l}\text { US } \\
\text { operator }\end{array}$ & $\begin{array}{l}\text { Study } \\
\text { setting }\end{array}$ & $\begin{array}{l}\text { US } \\
\text { equipment }\end{array}$ & $\begin{array}{l}\text { US diagnostic } \\
\text { criteria }\end{array}$ & $\begin{array}{l}\text { Time } \\
\text { between } \\
\text { reference } \\
\text { and US } \\
\end{array}$ \\
\hline $\begin{array}{l}\text { Banal } \\
{[18]}\end{array}$ & $7.5-13$ & $\begin{array}{l}\text { Metatar- } \\
\text { sal }\end{array}$ & $\begin{array}{l}\text { Double } \\
\text { blinded }\end{array}$ & MRI & $\begin{array}{l}\text { Experienced } \\
\text { rheumatolo- } \\
\text { gists }\end{array}$ & $\begin{array}{l}\text { Rheumatol- } \\
\text { ogy depart- } \\
\text { ment }\end{array}$ & $\begin{array}{l}\text { An Esaote } \\
\text { Technos } \\
\text { MP system }\end{array}$ & $\begin{array}{l}\text { Hypoechoic } \\
\text { periosteal elevation, } \\
\text { cortical disrup- } \\
\text { tion, and increased } \\
\text { vascularity }\end{array}$ & $\begin{array}{l}\text { The } \\
\text { same } \\
\text { day }\end{array}$ \\
\hline $\begin{array}{l}\text { Simanovsky } \\
{[19]}\end{array}$ & $5-12$ & Ankle & $\begin{array}{l}\text { Single } \\
\text { blinded }\end{array}$ & X-ray & $\begin{array}{l}\text { A pediatric } \\
\text { radiologist }\end{array}$ & $\begin{array}{l}\text { Emergency } \\
\text { department }\end{array}$ & $\begin{array}{l}\text { HDI } 5000 \\
\text { machine }\end{array}$ & $\begin{array}{l}\text { Discontinuity of the } \\
\text { echogenic cortical } \\
\text { line, cortical depres- } \\
\text { sion, and periosteal } \\
\text { elevation }\end{array}$ & NR \\
\hline $\begin{array}{l}\text { Canagasabey } \\
{[26]}\end{array}$ & NR & $\begin{array}{l}\text { Foot or } \\
\text { ankle }\end{array}$ & $\begin{array}{l}\text { Double } \\
\text { blinded }\end{array}$ & X-ray & $\begin{array}{l}\text { An emer- } \\
\text { gency } \\
\text { department } \\
\text { member }\end{array}$ & $\begin{array}{l}\text { Emergency } \\
\text { department }\end{array}$ & NR & $\begin{array}{l}\text { A significant frac- } \\
\text { ture was defined as } \\
\text { having a breadth } \\
\text { greater than } 3 \mathrm{~mm}\end{array}$ & NR \\
\hline $\begin{array}{l}\text { Hedelin } \\
{[27]}\end{array}$ & 15 & Ankle & $\begin{array}{l}\text { Double } \\
\text { blinded }\end{array}$ & X-ray & $\begin{array}{l}\text { Orthopedic } \\
\text { surgeons }\end{array}$ & $\begin{array}{l}\text { Emergency } \\
\text { department }\end{array}$ & $\begin{array}{l}\text { An } \\
\text { M-Turbo } \\
\text { Sonosite } \\
\text { system }\end{array}$ & NR & NR \\
\hline Ekinci [28] & 10 & $\begin{array}{l}\text { Foot or } \\
\text { ankle }\end{array}$ & $\begin{array}{l}\text { Single } \\
\text { blinded }\end{array}$ & X-ray & $\begin{array}{l}\text { An mergen- } \\
\text { cy physician }\end{array}$ & $\begin{array}{l}\text { Emergency } \\
\text { department }\end{array}$ & $\begin{array}{l}\text { A Logiq } \\
\text { Book XP } \\
\text { device }\end{array}$ & NR & NR \\
\hline Atilla [29] & 10 & $\begin{array}{l}\text { Foot } \\
\text { and/or } \\
\text { ankle }\end{array}$ & $\begin{array}{l}\text { Double } \\
\text { blinded }\end{array}$ & $\begin{array}{l}\text { X-ray or } \\
\text { CT }\end{array}$ & $\begin{array}{l}\text { A sonogra- } \\
\text { pher }\end{array}$ & $\begin{array}{l}\text { Emergency } \\
\text { department }\end{array}$ & $\begin{array}{l}\text { Mindray } \\
\text { M5 }\end{array}$ & $\begin{array}{l}\text { Cortical disruption } \\
\text { or stepping or axial } \\
\text { deviation on the } \\
\text { bone surface }\end{array}$ & NR \\
\hline $\begin{array}{l}\text { Yesilaras } \\
{[20]}\end{array}$ & $7.5-10$ & $\begin{array}{l}\text { The fifth } \\
\text { meta- } \\
\text { tarsal }\end{array}$ & $\begin{array}{l}\text { Double } \\
\text { blinded }\end{array}$ & X-ray & $\begin{array}{l}\text { An emergen- } \\
\text { cy physician }\end{array}$ & $\begin{array}{l}\text { Emergency } \\
\text { department }\end{array}$ & $\begin{array}{l}\text { Mindray } \\
\text { M5 }\end{array}$ & Cortical disruption & NR \\
\hline $\begin{array}{l}\text { Kozaci } \\
{[30]}\end{array}$ & 7.5 & $\begin{array}{l}\text { Meta- } \\
\text { tarsal }\end{array}$ & NR & X-ray & $\begin{array}{l}\text { Emergency } \\
\text { physicians }\end{array}$ & $\begin{array}{l}\text { Emergency } \\
\text { department }\end{array}$ & $\begin{array}{l}\text { Esaote } \\
\text { Firenze } \\
\text { Italy }\end{array}$ & Cortical disruption & NR \\
\hline $\begin{array}{l}\text { Ozturk } \\
{[31]}\end{array}$ & 10 & $\begin{array}{l}\text { Malleo- } \\
\text { lus }\end{array}$ & $\begin{array}{l}\text { Double } \\
\text { blinded }\end{array}$ & $\begin{array}{l}\text { X-ray or } \\
\text { CT }\end{array}$ & $\begin{array}{l}\text { Emergency } \\
\text { physicians }\end{array}$ & $\begin{array}{l}\text { Emergency } \\
\text { department }\end{array}$ & $\begin{array}{l}\text { Mindray } \\
\text { M7 }\end{array}$ & $\begin{array}{l}\text { A cortical irregular- } \\
\text { ity on one or more } \\
\text { plane }\end{array}$ & NR \\
\hline $\begin{array}{l}\text { Ebrahimi } \\
\text { [32] }\end{array}$ & 10 & $\begin{array}{l}\text { Meta- } \\
\text { tarsal }\end{array}$ & $\begin{array}{l}\text { Double } \\
\text { blinded }\end{array}$ & X-ray & $\begin{array}{l}\text { Emergency } \\
\text { medicine } \\
\text { specialist }\end{array}$ & $\begin{array}{l}\text { Emergency } \\
\text { department }\end{array}$ & NR & $\begin{array}{l}\text { Presence of cortical } \\
\text { disruption or } \\
\text { stepping or axial } \\
\text { deviation of } \\
\text { the bone surface }\end{array}$ & NR \\
\hline
\end{tabular}

NR, not reported; US, ultrasound; CT, computed tomography; MRI, magnetic resonance imaging

higher pooled specificity to countries other than Turkey (specificity: 0.96 and 0.88). All other sensitivity and specificity of subgroup analysis were similar.

The subgroup analysis of the eight studies [18,20,26$29,31,32]$ only including patients older than 14 years, demonstrated a pooled sensitivity of 0.96 (CI: 0.890.99 ) and specificity 0.94 (CI: 0.87-0.97). Furthermore, the subgroup analysis of the four studies [18,20,30,32] with respect to metatarsal fractures evidenced a pooled sensitivity of 0.94 (CI: 86-98) and specificity 0.90 (CI: 0.74-0.97). The results of the meta-regression are shown in Table III.

\section{Discussion}

So far, many studies have shown that ultrasound has a well diagnostic value for fractures in different sites. Gordon et al showed that point-of-care ultrasound had relatively high sensitivity of 0.91 and specificity of 0.96 for diagnosis in detecting skull fractures after pediatric head trauma [33]. Zhao et al demonstrated that ultrasound had an excellent diagnostic value for hand fractures, with a pooled sensitivity of 0.91 and specificity of 0.96 . Moreover, ultrasound was recommended as a first-line and radiation-free modality in detecting hand fractures [12]. 


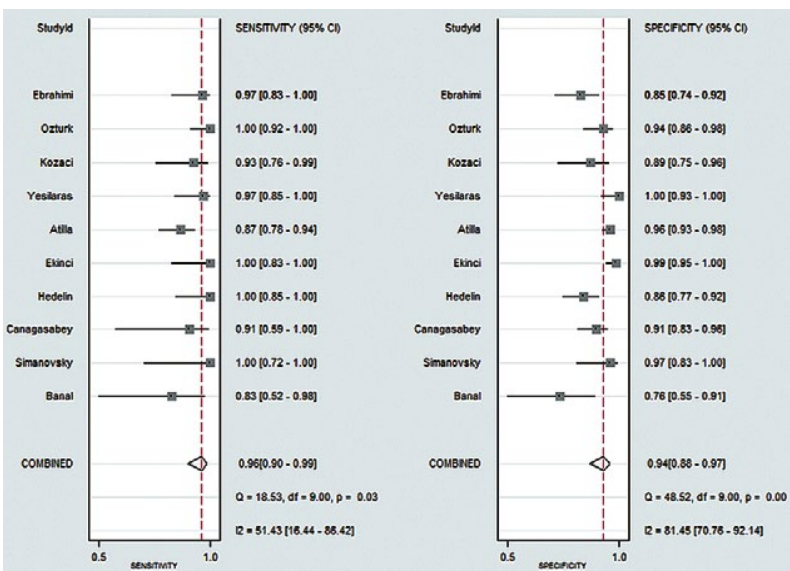

Fig 3. Forest diagrams of US diagnosing foot and ankle fractures, showing sensitivity and specificity

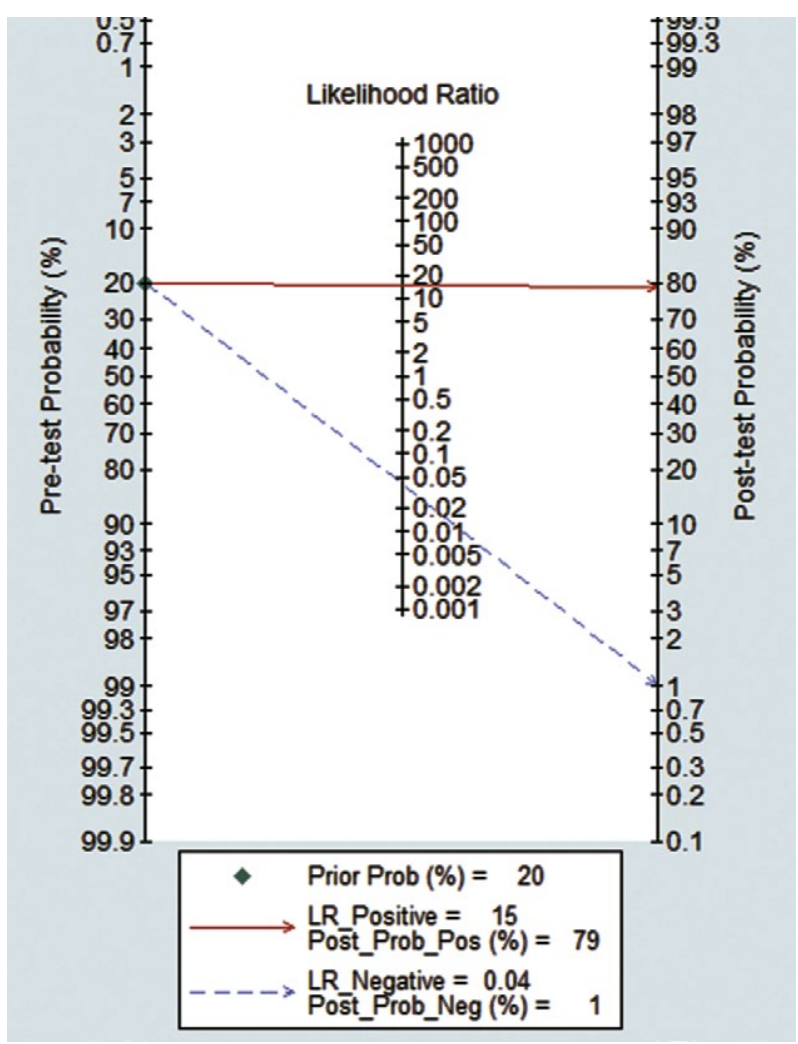

Fig 4. Fagan nomogram for detecting foot and ankle fractures

Lee et al reported that ultrasound sensitivity varied from 0.88 to 0.99 and specificity varied from 0.82 to 0.94 in elbow fracture in pediatric patients with trauma [9]. Chartier et al suggested that point-of-care ultrasound sensitivity varied from 0.65 to 1.00 and specificity varied from 0.79 to 1.00 in long bone fractures [34]. Douma-den et al reported that ultrasound had a perfect accuracy for the diagnosis of distal forearm fractures with a sensitivity of 0.97 and specificity of 0.95 , particularly in children [35].

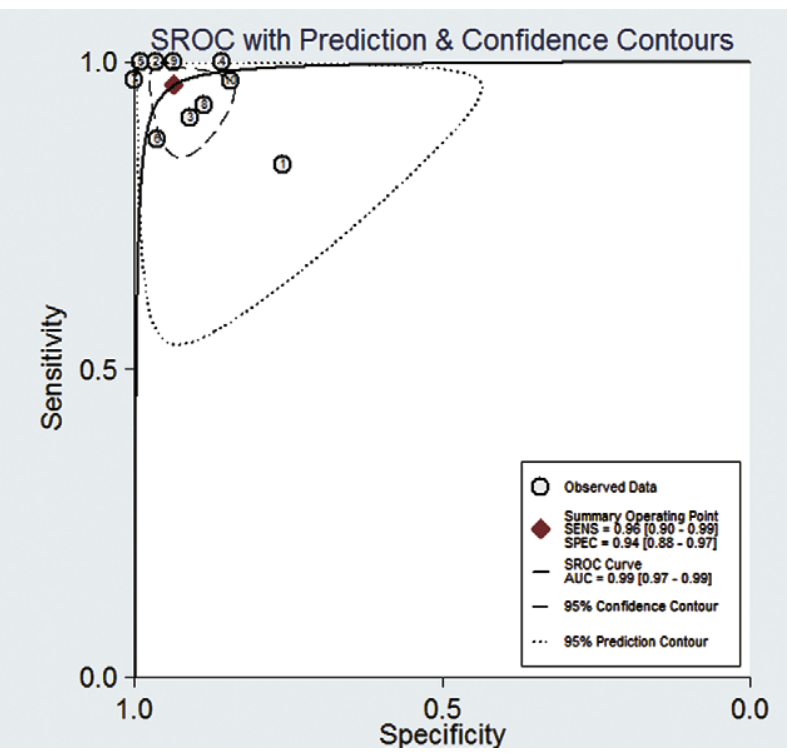

Fig 5. Summary receiver operating characteristics curve of US for foot and ankle fractures

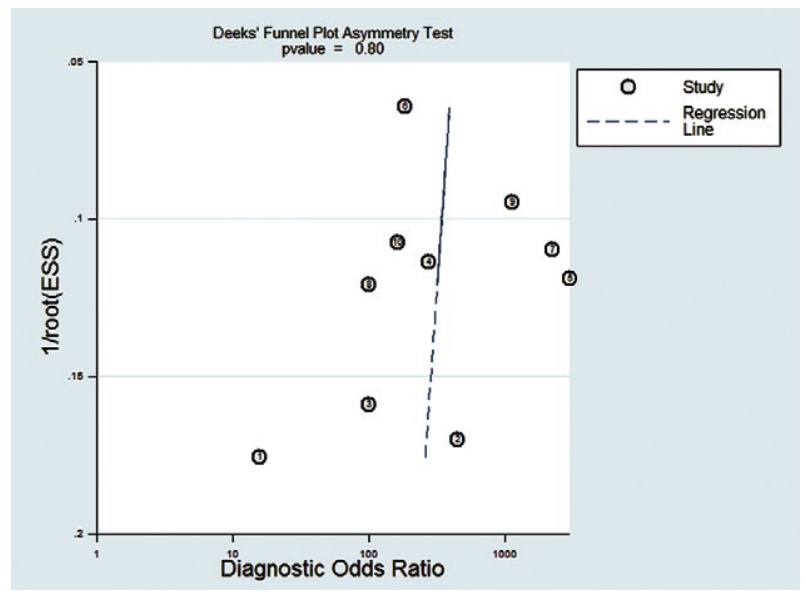

Fig 6. Funnel plot of US for foot and ankle fractures

So far, this is the first meta-analysis to evaluate the diagnostic performance of US for foot and ankle fractures. This meta-analysis provided a pooled sensitivity of 0.96 (95\% CI, 0.90-0.99), specificity of 0.94 (95\% CI, 0.880.97 ) and DOR of 367 (95\% CI, 101-1338), respectively, with an SROC AUC of 0.99 (95\% CI, 0.97-0.99). The findings of the present meta-analysis reveal that US has an excellent diagnostic value for foot and ankle fractures. Furthermore, the meta-analysis reveals a high PLR of 15.0 (95\% CI, 7.9-28.6) and a low NLR of 0.04 (95\% CI, $0.02-0.11$ ), suggesting that the diagnostic test performs well in correctly identifying the true disease conditions in patients with foot and ankle fractures. The previous review in adults identified the foot and ankle as the site of highest sensitivity and specificity across multiple studies, 
Table III. Meta-regression and subgroup analyses

\begin{tabular}{|c|c|c|c|c|c|}
\hline Covariate & No. of Studies & Sensitivity (95\% CI) & P Value & Specificity (95\% CI) & P Value \\
\hline Locale & & & 0.89 & & 0.16 \\
\hline Turkey & 5 & $0.96(0.92-1.00)$ & & $0.96(0.94-0.99)$ & \\
\hline Countries other than Turkey & 5 & $0.96(0.91-1.00)$ & & $0.88(0.82-0.93)$ & \\
\hline No. of patients & & & 0.99 & & 0.05 \\
\hline$\leq 100$ & 4 & $0.96(0.91-1.00)$ & & $0.91(0.82-0.99)$ & \\
\hline$>100$ & 6 & $0.96(0.91-1.00)$ & & $0.95(0.91-0.99)$ & \\
\hline Fracture prevalence, $\%$ & & & 0.44 & & 0.10 \\
\hline$\leq 30$ & 4 & $0.99(0.96-1.00)$ & & $0.95(0.89-1.00)$ & \\
\hline$>30$ & 6 & $0.94(0.89-0.99)$ & & $0.93(0.87-0.98)$ & \\
\hline Year published & & & 0.71 & & 0.33 \\
\hline 2009-2013 & 5 & $0.97(0.92-1.00)$ & & $0.93(0.86-0.99)$ & \\
\hline 2014-2019 & 5 & $0.96(0.91-1.00)$ & & $0.94(0.89-0.99)$ & \\
\hline Reference standard & & & 0.59 & & 0.51 \\
\hline Only radiograph & 7 & $0.97(0.94-1.00)$ & & $0.94(0.89-0.99)$ & \\
\hline Including $\mathrm{CT}$ or MRI & 3 & $0.92(0.84-1.00)$ & & $0.92(0.84-1.00)$ & \\
\hline US operator & & & 0.90 & & 0.48 \\
\hline Emergency physician & 5 & $0.97(0.95-1.00)$ & & $0.95(0.91-0.99)$ & \\
\hline Others & 5 & $0.91(0.85-0.96)$ & & $0.91(0.85-0.98)$ & \\
\hline US training & & & 0.93 & & 0.40 \\
\hline Yes & 6 & $0.96(0.92-1.00)$ & & $0.94(0.90-0.99)$ & \\
\hline Others & 4 & $0.96(0.91-1.00)$ & & $0.92(0.85-1.00)$ & \\
\hline Blinding method & & & 0.81 & & 0.04 \\
\hline Double blinding & 7 & $0.95(0.91-1.00)$ & & $0.92(0.87-0.97)$ & \\
\hline Others & 3 & $0.98(0.93-1.00)$ & & $0.97(0.92-1.00)$ & \\
\hline POCUS & & & 0.83 & & 0.18 \\
\hline Yes & 6 & $0.96(0.92-1.00)$ & & $0.93(0.88-0.98)$ & \\
\hline Others & 4 & $0.96(0.89-1.00)$ & & $0.94(0.88-1.00)$ & \\
\hline
\end{tabular}

POCUS, point-of-care ultrasound; US, ultrasound; CI, confidence interval

with values ranging from 85.9 to $100 \%$ and 86.4 to $100 \%$ respectively [11]. This is consistent with the results of our study.

As we all know, ultrasound is an operator-dependent technology [36]. Therefore, it is of the highest importance to ensure that operators acquire sufficient training and practice with this technology. With regard to the subgroup analysis of US training, operators with extra ultrasonographic training had a comparable diagnostic performance to others such as experience operators or not reported (sensitivity: 0.96 and 0.96; specificity: 0.94 and 0.92 ). However, the training protocols were variable among studies and the most of the training courses ranged from 30 minutes to 2 days [26,27,29-31]. It is undefined what the optimal training protocol is, so further prospective studies are required to determine the optimal training protocol and learning curve for this technology.

According to the eligible studies, the main ultrasonic characteristics of foot and ankle fractures included cortical disruption or stepping, axial deviation of the bone surface and cortical depression, which directly indicate fractures [19,20,26-32]. Other ultrasonic findings such as hypoechoic periosteal elevation, swollen soft tissues and increased vascularity, which are often not visualized by radiography also support foot and ankle fractures indirectly [18]. So further prospective studies with larger sample sizes are required to identify a well-defined protocol for ultrasound in detecting foot and ankle fractures.

Significant heterogeneity had been observed in this meta-analysis (sensitivity: $\mathrm{I}^{2}=51.43 \%, \mathrm{p}=0.03$; specificity: $\mathrm{I}^{2}=81.45 \%, \mathrm{p}=0.00$ ) and meta-regression analyses showed that the blinding method accounted for part of the significant sources of heterogeneity in terms of sensitivity. However, there were other factors which might involve the significant heterogeneity. Other factors such as specialties of ultrasonic operators, different experience levels and different equipment might also play an important role in heterogeneity among studies. However meta-regression analyses could not be performed to explore the significant sources of heterogeneity according to other factors referred above because of the insufficient information in the included studies. 
Most of the included studies chose conventional $\mathrm{X}$-ray as the reference standard, which is not the golden standard to detect fractures. Because occult fractures account for $2 \%-36 \%$ in a conventional X-ray on account of overlapping structures, under-mineralized ossification centres and non-perpendicular X-ray beam to the fracture line [35]. Several studies have demonstrated that multiplanar capabilities of ultrasound might make it superior to radiography in the detection of occult fractures that the $\mathrm{X}$-ray has missed $[37,38]$. Banal et al found that in cases of normal radiographs, US is indicated in the diagnosis of metatarsal bone stress fractures with a sensitivity of 0.83 and a specificity of 0.76 [18]. The prospective study of ultrasonographic evaluation of radiographically negative ankle injuries in a pediatric population performed by Simanovsky et al demonstrated that ultrasound is effective in the detecting radiographically silent fractures of the pediatric ankle with a sensitivity of 1.00 and a specificity of 0.97 [19]. In future, studies adopting CT or MRI as the golden standard are required to evaluate the diagnostic performance of ultrasound in detecting radiographically occult fractures.

Atilla et al showed that the sensitivity and specificity of US for foot and ankle fractures could vary according to the fracture site. US had excellent sensitivity and specificity in the diagnosis of the fifth metatarsal fractures with a sensitivity of 1.00 and specificity of 0.96 , which might be explained by the superficial site of the fifth metatarsal and its smooth contours and ease of viewing from different planes by US; while the sensitivity and specificity of US for detecting navicular fractures was relatively lower (sensitivity: 0.40 and specificity: 0.93 ) as the dorsal surface of the navicular bone is irregular and could only be viewed in the dorsal plane [29]. Our subgroup analysis of the 4 studies only including metatarsal fractures $[18,20,30,32]$ showed pooled sensitivity of 0.95 and specificity of 0.90 . However, we faced insufficient data to perform more subgroup analyses regarding different fracture sites such as ankle fractures or navicular fractures.

Foot and ankle injuries are almost universally assessed by the Ottawa Foot and Ankle Rules, which have a reported sensitivity of $97.9 \%$ to $99.8 \%$ and a specificity of $28.8 \%$ and $42.3 \%$ for foot and ankle fractures respectively [39-42]. The poor specificity of the rules indicates that about $60 \%$ of patients who undergo a radiograph do not have a fracture, with many patients exposed to unnecessary harmful ionizing radiation. Hedelin et al suggested ultrasound-guided triage seemed to be able to decrease the need for radiographic imaging in patients with ankle trauma [27]. Similarly, Canagasabey et al suggested that US examination had been employed prior to the X-ray, the quantity of radiographs needed would have fallen by $80.9 \%$ [26]. Consequently, US is increasingly being considered as a first-line modality in the primary response to emergency situations and could decrease the need for radiographic imaging in patients with foot and ankle fractures.

It is important to consider some limitations with respect to this study. First, a relatively small number of studies were included in the present meta-analysis as a result of the limited relevant high-quality studies, and the literature search merely included studies written in English. Anyway, we were able to acquire several important conclusions with respect to the diagnostic value of US and related factors. Second, most of the eligible studies failed to report the precise duration between the standard reference and US examination except for the study by Banal et al who declared that US and dedicated MRI examinations of the metatarsal bones were performed the same day [18]. However, the reference standard and US performed without a narrow time frame may not increase the performance bias because fractures will not change over time in the short term. Third, no study evaluated intraobserver or interobserver variability; however, it is important to do so because ultrasound is an operatordependent modality. Therefore, more further studies are required to evaluate the intraobserver or interobserver variability. Finally, most of the included studies had methodological limitations, especially in domains such as patient selection, the index test, reference standard and flow and timing, and therefore improvements in the future study design are required to accurately address the issue under investigation.

\section{Conclusions}

In summary, this comprehensive meta-analysis demonstrates that ultrasound has an excellent diagnostic performance for foot and ankle fractures and should be considered as a primary and radiation-free scanning modality in the diagnosis of foot and ankle fractures. However, the conclusion of this meta-analysis on the strength of a small quantity of studies that met the specific inclusion criteria should be interpreted with caution. Large prospective international multicenter studies are still required to support the present conclusion.

\section{Conflict of interest: none}

\section{References}

1. Shibuya N, Davis ML, Jupiter DC. Epidemiology of foot and ankle fractures in the United States: an analysis of the National Trauma Data Bank (2007 to 2011). J Foot Ankle Surg 2014;53:606-608. 
2. Crowley SG, Trofa DP, Vosseller JT, et al. Epidemiology of foot and ankle injuries in National Collegiate Athletic Association men's and women's ice hockey. Orthop J Sports Med 2019;7:2325967119865908.

3. Wood JN, Henry MK, Berger RP, et al. Use and utility of skeletal surveys to evaluate for occult fractures in young injured children. Acad Pediatr 2019;19:428-437.

4. Nery C, Raduan F, Baumfeld D. Foot and ankle injuries in professional soccer players: diagnosis, treatment, and expectations. Foot Ankle Clin. 2016;21:391-403.

5. Ait-Ali L, Andreassi MG, Foffa I, Spadoni I, Vano E, Picano E. Cumulative patient effective dose and acute radiation-induced chromosomal DNA damage in children with congenital heart disease. Heart 2010;96:269-274.

6. Brenner DJ, Doll R, Goodhead DT, et al. Cancer risks attributable to low doses of ionizing radiation: assessing what we really know. Proc Natl Acad Sci U S A 2003;100:1376113766.

7. LiMarzi GM, Scherer KF, Richardson ML, et al. CT and MR imaging of the postoperative ankle and foot. Radiographics 2016;36:1828-1848.

8. Beard NM, Gousse RP. Current ultrasound application in the foot and ankle. Orthop Clin North Am 2018;49:109121.

9. Lee SH, Yun SJ. Diagnostic performance of ultrasonography for detection of pediatric elbow fracture: a meta-analysis. Ann Emerg Med 2019;74:493-502.

10. Douma-den Hamer D, Blanker MH, Edens MA, et al. Ultrasound for distal forearm fracture: a systematic review and diagnostic meta-analysis. PLoS One 2016;11:e0155659.

11. Champagne N, Eadie L, Regan L, Wilson P. The effectiveness of ultrasound in the detection of fractures in adults with suspected upper or lower limb injury: a systematic review and subgroup meta-analysis. BMC Emerg Med 2019;19:17.

12. Zhao W, Wang G, Chen B, et al. The value of ultrasound for detecting hand fractures: A meta-analysis. Medicine (Baltimore) 2019;98:e17823.

13. Mircea PA, Badea R, Fodor D, Buzoianu AD. Using ultrasonography as a teaching support tool in undergraduate medical education - time to reach a decision. Med Ultrason 2012;14:211-216.

14. Saul T, Ng L, Lewiss RE. Point-of-care ultrasound in the diagnosis of upper extremity fracture-dislocation. A pictorial essay. Med Ultrason 2013;15:230-236.

15. Sconfienza LM, Albano D, Allen G, et al. Clinical indications for musculoskeletal ultrasound updated in 2017 by European Society of Musculoskeletal Radiology (ESSR) consensus. Eur Radiol 2018;28:5338-5351.

16. Zayat AS, Md Yusof MY, Wakefield RJ, Conaghan PG, Emery P, Vital EM. The role of ultrasound in assessing musculoskeletal symptoms of systemic lupus erythematosus: a systematic literature review. Rheumatology (Oxford) 2016;55:485-494.

17. Zhang CM, Zhang JF, Xu J, Guo YL, Wang G, Yang LH. Musculoskeletal ultrasonography for arthropathy assessment in patients with hemophilia: A single-center cross- sectional study from Shanxi Province, China. Medicine (Baltimore) 2018;97:e13230.

18. Banal F, Gandjbakhch F, Foltz V, et al. Sensitivity and specificity of ultrasonography in early diagnosis of metatarsal bone stress fractures: a pilot study of 37 patients. J Rheumatol 2009;36:1715-1719.

19. Simanovsky N, Lamdan R, Hiller N, Simanovsky N. Sonographic detection of radiographically occult fractures in pediatric ankle and wrist injuries. J Pediatr Orthop 2009;29:142-145.

20. Yesilaras M, Aksay E, Atilla OD, Sever M, Kalenderer O. The accuracy of bedside ultrasonography as a diagnostic tool for the fifth metatarsal fractures. Am J Emerg Med 2014;32:171-174.

21. Shamseer L, Moher D, Clarke M, et al. Preferred reporting items for systematic review and meta-analysis protocols (PRISMA-P) 2015: elaboration and explanation. BMJ 2015;350:g7647.

22. Whiting PF, Rutjes AW, Westwood ME, et al. QUADAS-2: a revised tool for the quality assessment of diagnostic accuracy studies. Ann Intern Med 2011;155:529-536.

23. Hanley JA, McNeil BJ. The meaning and use of the area under a receiver operating characteristic (ROC) curve. Radiology 1982;143:29-36.

24. Higgins JP, Thompson SG, Deeks JJ, Altman DG. Measuring inconsistency in meta-analyses. BMJ 2003;327:557560.

25. Deeks JJ, Macaskill P, Irwig L. The performance of tests of publication bias and other sample size effects in systematic reviews of diagnostic test accuracy was assessed. J Clin Epidemiol 2005;58:882-893.

26. Canagasabey MD, Callaghan MJ, Carley S. The sonographic Ottawa Foot and Ankle Rules study (the SOFAR study). Emerg Med J 2011;28:838-840.

27. Hedelin H, Goksör LÅ, Karlsson J, Stjernström S. Ultrasound-assisted triage of ankle trauma can decrease the need for radiographic imaging. Am J Emerg Med 2013;31:16861689.

28. Ekinci S, Polat O, Günalp M, Demirkan A, Koca A. The accuracy of ultrasound evaluation in foot and ankle trauma. Am J Emerg Med 2013;31:1551-1555.

29. Atilla OD, Yesilaras M, Kilic TY, et al. The accuracy of bedside ultrasonography as a diagnostic tool for fractures in the ankle and foot. Acad Emerg Med 2014;21:10581061.

30. Kozaci N, Ay MO, Avci M, et al. The comparison of radiography and point-of-care ultrasonography in the diagnosis and management of metatarsal fractures. Injury 2017;48:542-547.

31. Ozturk P, Aksay E, Oray NC, Bayram B, Basci O, Tokgoz D. Emergency physician accuracy using ultrasonography to diagnose lateral malleolar fracture. Am J Emerg Med 2018;36:362-365.

32. Ebrahimi M, Habibzadeh SR, Ahmadi SR, Khajeh Nasiri S, Kaveh MM, Foroughian M. Diagnostic Accuracy of Ultrasonography in Diagnosis of Metatarsal Bone Fracture; a Cross Sectional Study. Arch Acad Emerg Med 2019;7:e49. 
33. Gordon I, Sinert R, Chao J. The utility of ultrasound in detecting skull fractures after pediatric blunt head trauma: systematic review and meta-analysis. Pediatr Emerg Care 2020, doi:10.1097/PEC.0000000000001958.

34. Chartier LB, Bosco L, Lapointe-Shaw L, Chenkin J. Use of point-of-care ultrasound in long bone fractures: a systematic review and meta-analysis. CJEM 2017;19:131-142.

35. Douma-den Hamer D, Blanker MH, Edens MA, et al. Ultrasound for distal forearm fracture: a systematic review and diagnostic meta-analysis. PLoS One 2016;11:e0155659.

36. Scheel AK, Schmidt WA, Hermann KG, et al. Interobserver reliability of rheumatologists performing musculoskeletal ultrasonography: results from a EULAR "Train the trainers" course. Ann Rheum Dis 2005;64:1043-1049.

37. Kwee RM, Kwee TC. Ultrasound for diagnosing radiographically occult scaphoid fracture. Skeletal Radiol 2018;47:1205-1212.
38. Allen GM, Wilson DJ, Bullock SA, Watson M. Extremity CT and ultrasound in the assessment of ankle injuries: occult fractures and ligament injuries. Br J Radiol 2020;93:20180989.

39. Bachmann LM, Kolb E, Koller MT, Steurer J, ter Riet G. Accuracy of Ottawa ankle rules to exclude fractures of the ankle and mid-foot: systematic review. BMJ 2003;326:417.

40. Auleley GR, Ravaud P, Giraudeau B, et al. Implementation of the Ottawa ankle rules in France. A multicenter randomized controlled trial. JAMA 1997;277:1935-1939.

41. Lucchesi GM, Jackson RE, Peacock WF, Cerasani C, Swor RA. Sensitivity of the Ottawa rules. Ann Emerg Med 1995;26:1-5.

42. Beckenkamp PR, Lin CC, Macaskill P, Michaleff ZA, Maher CG, Moseley AM. Diagnostic accuracy of the Ottawa Ankle and Midfoot Rules: a systematic review with metaanalysis. Br J Sports Med 2017;51:504-510. 